\title{
Comparative Evaluation of Cellular Response to Three Types of Zolid Surface Full Contour: Glazing, Polishing, and CO2 Laser
}

\author{
A. Shishehian ${ }^{1}$, A. izadi ${ }^{1}$, S. Abbasi ${ }^{1}$, S. Khazai ${ }^{1} \&$ S. Nik anjam² \\ ${ }^{1}$ Assistant Professor, Dept of Prosthodontics, School of Dentistry, Hamadan University of Medical Sciences, \\ Hamadan, Iran \\ ${ }^{2}$ Post graduate student of prosthodontics, Hamadan University of Medical Sciences, Hamadan, Iran \\ Correspondence: S. Nik anjam, Post graduate student of prosthodontics, Hamadan University of Medical Sciences, \\ Hamadan, Iran. E-mail: hamunidentist@gmail.com
}

Received: June 13, 2018

Accepted: June 25, 2018

Online Published: July 3, 2018

doi:10.5539/jmbr.v8n1p53

URL: https://doi.org/10.5539/jmbr.v8n1p53

\begin{abstract}
Background: Zirconia ceramics have recently been widely used in dentistry because these materials are very favorable for chemical, dimensional stability, mechanical strength and hardness, Zolid FX (Ceramill Zolid FX, Amann Girrbach AG) is a type of zirconia. In this study, we have tried to measure the effects of different methods of surface preparation of full-contour restoration on the degree of material release and cellular response, so that we can recommend a method with lower tissue damage.
\end{abstract}

Methods: In this study, Twenty blocks were prepared by CAD / CAM with dimensions of $5.5 \mathrm{~mm}$ in diameter and $3 \mathrm{~mm}$ in thickness and randomly divided into four groups. The laser used in this study is a co2 laser (Ultradream pluse, guro-gu seul, Korea). Comparison of the groups with the intact group was carried out two by two. The control group was compared by ANOVA and the groups with significant differences (with a significant percentage of 0.05) were compared by TUKEY statistical test.

Conclusion and Results: Delivering one-stage, non-glazed-polished zirconium restorations can result in incompatible cellular response and is detrimental to the health of the periodontal tissue surrounding the restoration. It is also recommended that if the restoration due to the adjusting of clinician lose the glazed layer should not be delivered intact, at least prepare by polishing method, also if the laser is available in the clinic, then the surface restoration will be prepare using it, although it has not been routinely used due to lesser access to lasers in clinics.

Keywords: cellular response, zolid surface full contour, glazing, polishing, $\mathrm{CO} 2$ laser

\section{Introduction}

Dental ceramics have been developed since 1774 as important ingredients in restorative dentistry (Giordano., 1996). Today, the use of cosmetic materials is more common in dentistry; ceramics are one of the important materials in this group (Denry., 1996). These materials are excellent in terms of biocompatibility and durability, and also beautifully. The smooth and gelatinized wrinkles reduce plaque buildup and therefore reduce gingivitis. Porcelain biocompatibility as well as surface fineness makes the probability of inflammation of the gum drastically reduced when the finish line is located subgingival (Anusavice., 1993). Zirconia ceramics have recently been widely used in dentistry because these materials are very favorable for chemical, dimensional stability, mechanical strength and hardness. Zolid FX (Ceramill Zolid FX, Amann Girrbach AG) is a type of zirconia that has been introduced as a substitute for lithium disilicate and is also an ideal option for full contour crown of the anterior region due to its prominent optical properties. With the development of CAD / CAM and planning for singlesession treatments, the use of zirconium has been developed (Oliva et al., 2010; Kohal et al., 2004).

After the ceramic firing, the resulting superficial violence increases plaque adhesion, surface color changes, and fatigue failure in the restorative material. Different methods have been developed to reduce surface irritation, including glazing, polishes and lasers. Therefore, glaze and polish are superficial treatments that reduce the surface harshness of the ceramic surface and subsequently reduces plaque accumulation and subsequently reduces the probability of gingivitis (Kohal et al., 2004). Polishing using a mullet creates a smooth surface in zirconia restorations, which causes plaque not to accumulate and prevents gingivitis. In this polish, various mullets have been used. Studies have shown that the use of polish by mullet of amalgam restoration improves the retention rate 
and prevents the accumulation of bacteria and plaque (Rashid., 2014). Glaze of porcelain restorations using a new co2 laser is novel method to create a smooth surface at the porcelain surface and prevent plaque accumulation and gingivitis. Some studies have shown that co2 laser without a change in porcelain structure creates a ceramic smooth surface (Amaya-Pajares et al., 2016). In a standardized temperature glaze method, the underneath ceramic becomes more shrunk when cooled, and compression stress is created at the surface of the glued porcelain. This surface compression stress increases the porcelain strength by preventing the cracks from extending to the porcelain depth, and, by creating a smooth surface in the ceramic, prevents the accumulation of plaque in the ceramic surface (Bartolo et al., 2017).

In vitro tests for evaluation of the dentistry compatibility have mostly been conducted on metals and composites, and ceramics have fewer been evaluated, the amount of material loss in different ceramics is different and nonuniform, and few studies on the effect of this release is done. In this study, we have tried to measure the effects of different methods of surface preparation of full-contour restoration on the degree of material release and cellular response, so that we can recommend a method with lower tissue damage.

\section{Materials and Methods}

In this study, zolid FX (Ceramill Zolid FX, Amann Girrbach AG) was used. (Table 1). Twenty blocks were prepared by CAD / CAM with dimensions of $5.5 \mathrm{~mm}$ in diameter and $3 \mathrm{~mm}$ in thickness. The samples were evaluated under light and magnified 10 times for any problem including bubble cracking or defect. Then, samples were taken in an acrylic generator and were mounted by a polishing mill (\# 2134, KG Sorensen, Brazil) was prepared with average strength and uniform pressure of hand. At this stage, it was tried to preserve the shape of the samples and remove the thickness of about $0.2 \mathrm{~mm}$ from the samples. After that, the thickness of the samples was evaluated and sub-enlarged. The samples were washed with isopropyl alcohol and then plated in an ultrasonic cleaner (Branson, Model 1210) and washed with sterile water and randomly divided into four groups

Table 1. Zolid Fx ceramic chemical compounds

\begin{tabular}{ll}
\hline Zolid Fx & Percentage of each component \\
\hline ZrO2 $+\mathrm{HfO} 2+\mathrm{Y} 2 \mathrm{O} 3$ & $\mathbf{2 9 9 . 0}$ \\
$\mathrm{Y} 2 \mathrm{O} 3$ & $\mathbf{9 . 1 5 - 9 . 5 5}$ \\
$\mathrm{HfO} 2$ & $\leq \mathbf{5}$ \\
$\mathrm{A} 2 \mathrm{O} 3$ & $\leq \mathbf{0 , 5}$ \\
Other oxides & $\leq \mathbf{1}$ \\
\hline
\end{tabular}

Group 1: By using the zolid special glaze liquid introduced by the factory (glazed group). The glazed samples (with special liquid) were examined for surface properties under a SEM microscope. (Figure 1)

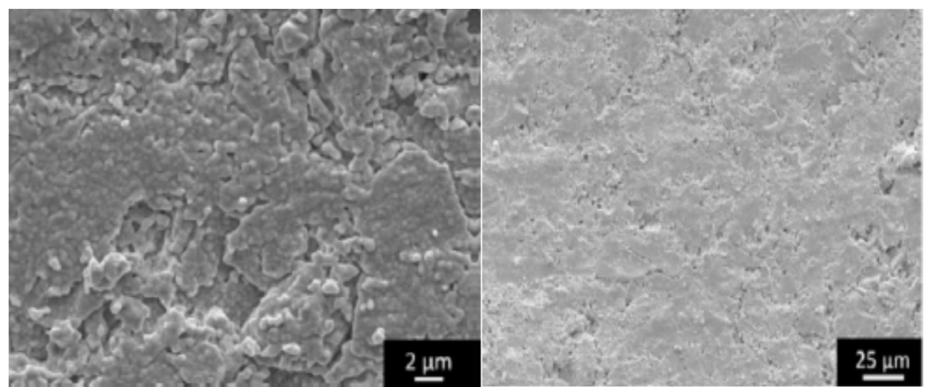

Figure 1. Glazed group under magnification with electron microscope (SEM)

The second group: By using a kit were polished, for this purpose, the (amann-girrbach Asia pte ltd) ceramil polishdent kit, which included two wheel tires and two cup rubber with medium and fine grain size. First, the medium type was driven by the parasite with hand-pressure and then finely shaped in the same order for polishing. The polishes were sampled after polishing for evaluation of surface properties under a SEM microscope (Giordano et al., 1994). (Figure 2) 


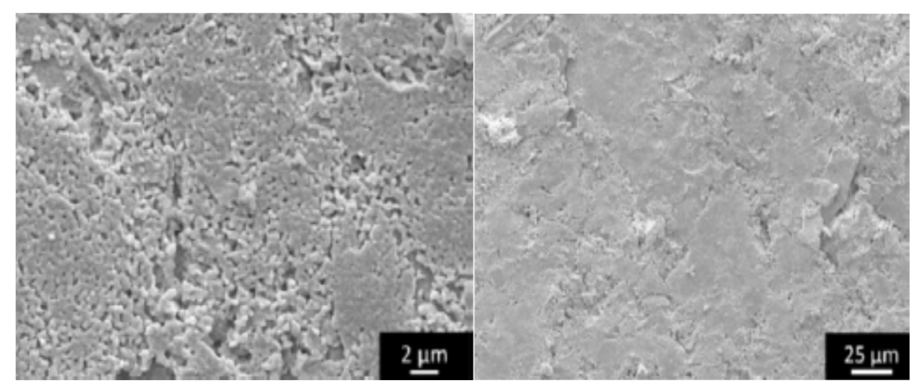

Figure 2. Polished group under magnification electron microscope (SEM)

Group 3: The samples were glazed by laser radiation. The laser used in this study is a co2 laser

(Ultra-dream pluse, guro-gu seul, Korea) with wavelengths ( 6 and 10 micrometers) with 30 watts of power and a one- minute continuous exposure time of $8 \mathrm{~mm}$ were taken continuously on samples that are placed on a refractory base, as well as a $0.5 \mathrm{~mm}$ dot laser spot and the speed was $10 \mathrm{~mm} / \mathrm{min}$ (Figure 3 ).

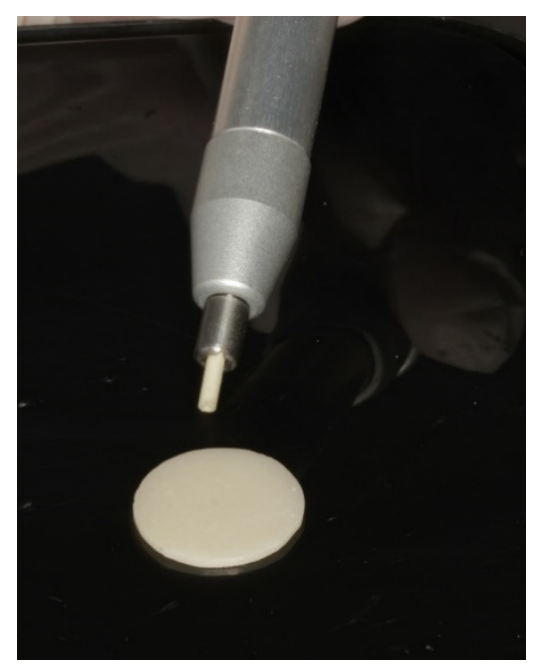

Figure 3. Co2 laser and Zolid Fx sample

The samples were examined after laser glaze to evaluate surface properties under a SEM microscope (Hammouda et al., 2014) (Laser group) (Figure 4).

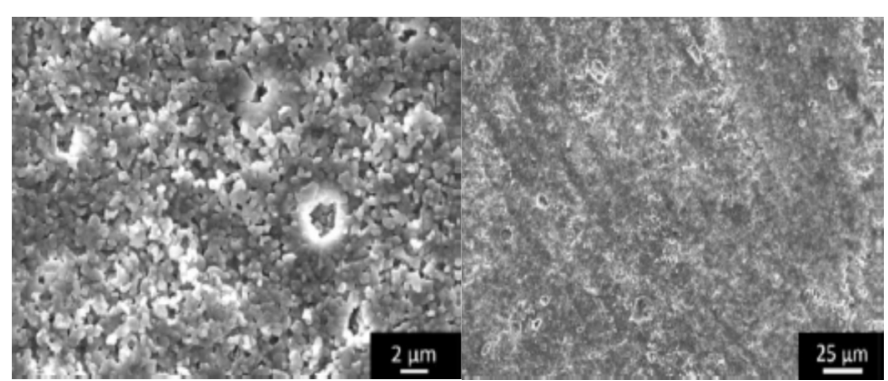

Figure 4. Laser group under magnification electron microscope (SEM)

Group 4: The samples remained intact without superficial treatment (intact group). The samples were examined for surface properties under a SEM microscope (Figure 5). 


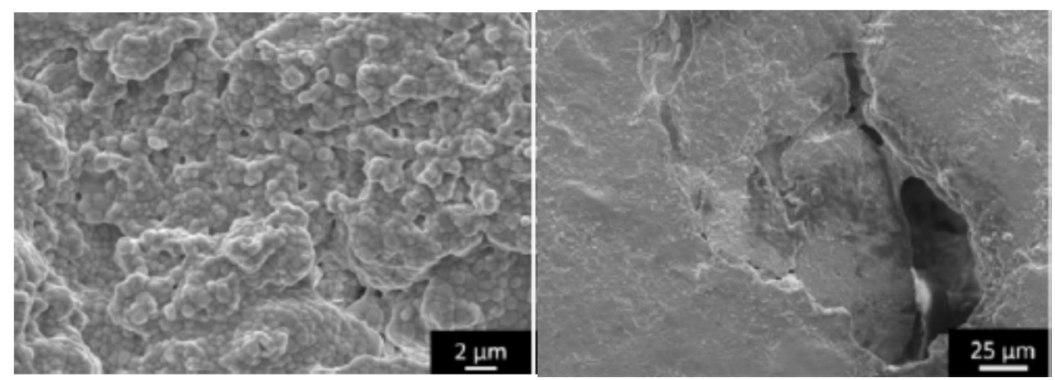

Figure 5. Intact group under magnification with electron microscope (SEM)

\subsection{Cell Culture Medium}

Regarding the fact that the restoration has performances in the mouth for a long time, the samples were placed in an ultrasonic cleaner and washed in distilled water in an aging chemical solution including BSA serum for 96 hours (Giordano et al., 1994). This serum has been used effectively in many studies. The aging stage is used to accurately simulate the long-term use of dental materials, as well as the rapid release of pieces of material such as corrosion (Sasaki et al., 2015) and a similar state of substance reaction within 8 to 10 months in the body. After this period, the samples were removed and washed with isopropyl alcohol in an ultrasonic cleaner and washed in distilled water and tested by cellulose testing using the recommended standard iso 10993 (Medium containing Dulbecco modified eagle medium with $3 \%$ NuSerum, gentamycin $(10 \mathrm{~g} / \mathrm{ml})$, penicillin $(100 \mathrm{units} / \mathrm{ml})$, streptomycin $(100 \mathrm{~g} / \mathrm{ml})$, glutamine $(2 \mathrm{mmol} / \mathrm{L}))$. Sticky cells are incubated in a logarithmic phase with a mixture of $0.025 \%$ trypsin, $0.02 \%$ ethylene diamine tetra acetic acid (EDTA), at $37^{\circ} \mathrm{C}$ for $2-5$ minutes (Sabaliauskas et al., 2011) and used for cell culture. The surface area ratio to the sample size is approximately $151 \mathrm{~mm}^{2} / \mathrm{ml}$ and the samples were kept in contact with the medium for 72 hours. All specimens were stored separately and in similar conditions. After 72 hours, samples were taken out by MTT (3- [4, 5-dimethyl- thiazolyl-] - [2,5diphenyl tetrazolium bromide). In this method, the cellular response is based on the activity of mitochondrial succinate dehydrogenase (SHD), the activity of SHD indicates the viability and activity of cells around zirconium discs after the cells was contacted for 72 hours. The cells were rinsed by phosphate buffered saline solution. MTT solution $\left(1 \mathrm{mg} / \mathrm{ml}\right.$, sodium succinate buffer, sigma St. Louis. MO) was added, and the environments were incubated at $37^{\circ}$ $\mathrm{C}$ for 45 minutes. During this period, the activated mitochondria became yellow, soluble MTT into intracellular blue, and the unmixed MTT remained formazan. After this stage, the cells were fixed with Tris-buffered formalin $(4 \%, \mathrm{pH} 7.2)$ and then rinsed with distilled water. Finally, the MTT-formazan was dissolved in dimethyl sulfoxide (Sigma) and the optical density of the resulting solution was read at $562 \mathrm{~nm}$ using a plate reader (Vmax; Molecular Devices, Menlo Park, Calif). The results are expressed as the percentage of cell survival. Samples were evaluated after one day and one week.

\subsection{Statistical Analysis}

Comparison of the groups with the intact group was carried out two by two. The control group was compared by ANOVA and the groups with significant differences (with a significant percentage of 0.05 ) were compared by TUKEY statistical test.

\section{Results}

Intact zirconia has a limiting effect on SDH activity of mitochondria, to the extent that this anti-SDH activity can be cited as a cytotoxic effect (Table 2).

Although the disk-polished zirconium has some anti-inhibitory effect on mitochondrial SDH activity, this difference was significant with the intact group.

Zirconium laser glazed has the least inhibitory effect on mitochondrial SDH activity after one week, thereafter was the inhibitory effect on the mitochondrial SDH activity of the glazed samples with the factory special fluid (Figure $1)$. 
Table 2. Results of cell survival test

\begin{tabular}{lcc}
\hline Samples & After 3 days & After one week \\
\hline Glazed group with special liquid & $\mathbf{9 8} \pm \mathbf{1 . 6} \%$ & $\mathbf{9 7 . 1} \pm \mathbf{0 . 9} \%$ \\
Polished group & $\mathbf{9 7} \pm \mathbf{2} \%$ & $\mathbf{9 6 . 1} \pm \mathbf{1 . 3} \%$ \\
Glazed group with $\mathrm{CO}_{2}$ laser & $\mathbf{9 9 . 2} \pm \mathbf{1 . 7} \%$ & $\mathbf{9 8 . 2} \pm \mathbf{0 . 7} \%$ \\
Intact group & $\mathbf{9 6 . 2} \pm \mathbf{3} \%$ & $\mathbf{9 4 . 1} \pm \mathbf{1 . 2} \%$ \\
\hline
\end{tabular}

The difference between the anti-SDH activities of the mitochondria between the two groups of glazed with factory glaze liquid and glazed by laser was not significant, but these samples had a significant difference with the intact group, although this inhibitory effect of SDH mitochondria had no significant difference with the polished group with disc.

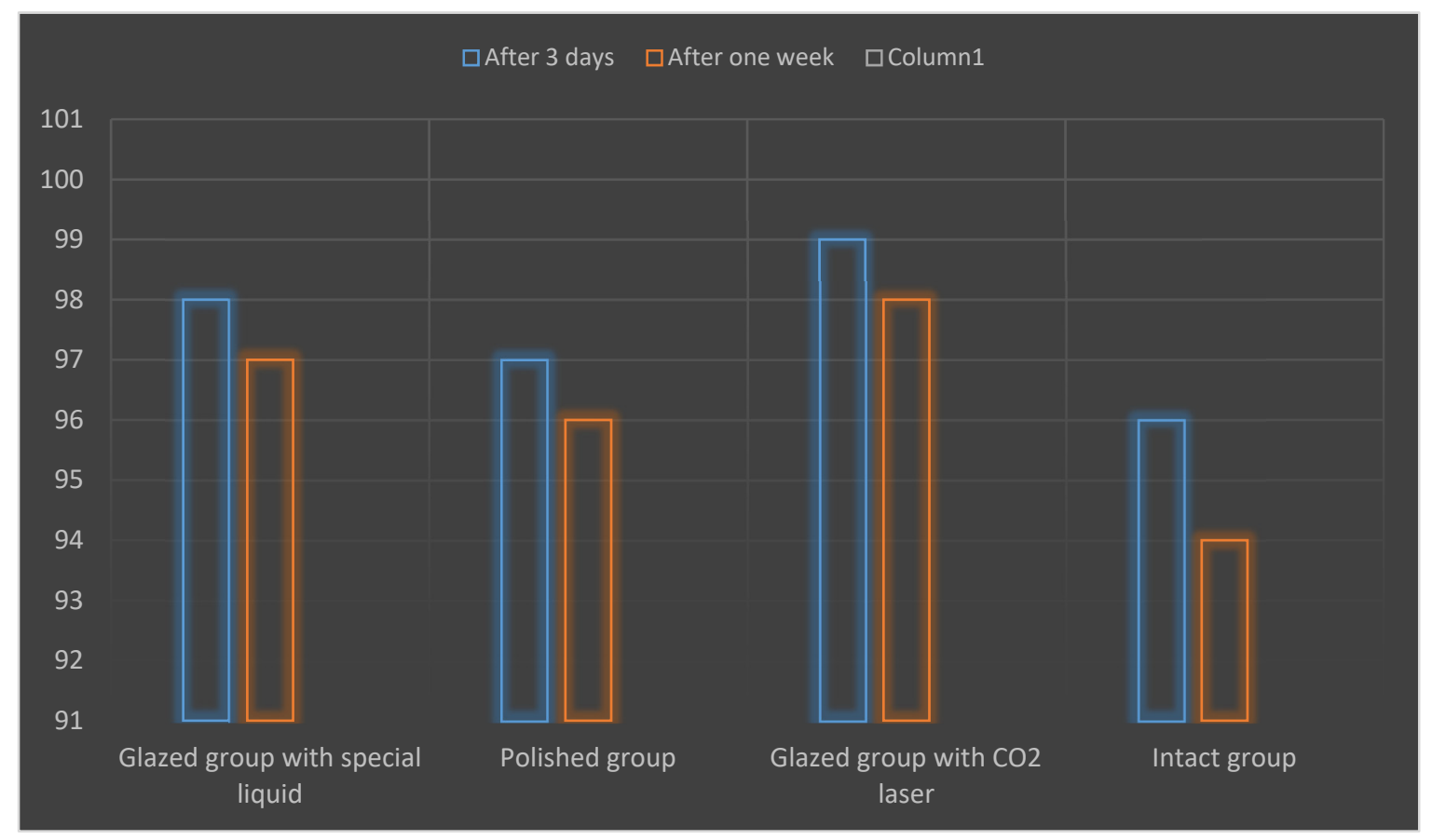

Chart 1: The amount of cell survival

\section{Discussion}

Fibroblasts have been used extensively to evaluate the cytotoxicity of prosthetic materials. Other methods, such as the method of agar coating, and the filtering test method, are also used to evaluate the toxicity level. However, the proposed methods of evaluation are evaluated through the level of MMP activity to assess the amount of chromogen and cytotoxicity is most often used (Brackett et al., 2008; Sjögren et al., 2000).

Based on the findings of this study, it seems that method of the surface preparation of zirconia samples is effective on the amount of cellular response, especially with regard to the long-term use of oral rehabilitation and the aging process. The cellular response can be changed over time. The studies on toxicity of ceramics show less primary toxicity on fibroblasts (Messer et al., 2003).

In- vitro tests conducted by cell culture environments on a variety of disk or powder forms of zirconium reveals that this substance is less sensitive to acute responses, although it should be emphasized that the results of these tests are essentially based on the form of the tested substance such as the surface shape, structural form, chemical structure and impurities (Etman et al., 2010).

The effect of the physical properties of ceramics on the level of cellular activity and bioavailability has been evaluated and it has been shown that powder types are more toxic than dens types, although this type of material is less similar to clinical conditions, it is suggested that tests on disk samples (Martinez-Rus et al., 2011). 
It should be noted that due to the uniformity of the tested material in all specimens, and simply the difference in the methods for preparing a different cellular response, it is related to the type of surface preparation.

Considering the findings of this study and the observed cellular response to the intact zirconium samples, the general belief is that these materials are inactive and biocompatible is questionable, because the amount of inhibition of cells by this group is considered as a threat to health. Due to the potential for release of Molecules from this material, the cellular response may be altered (Wang et al., 2010) (Figure 6).

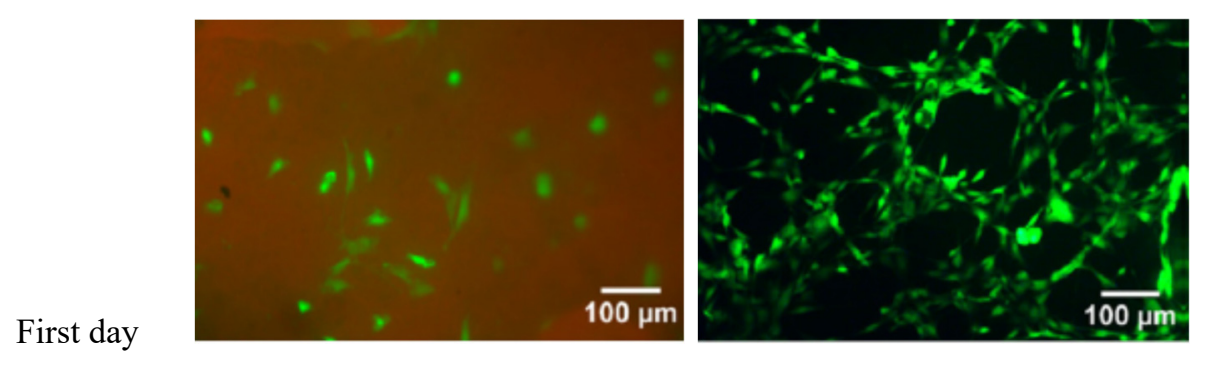

Seventh day

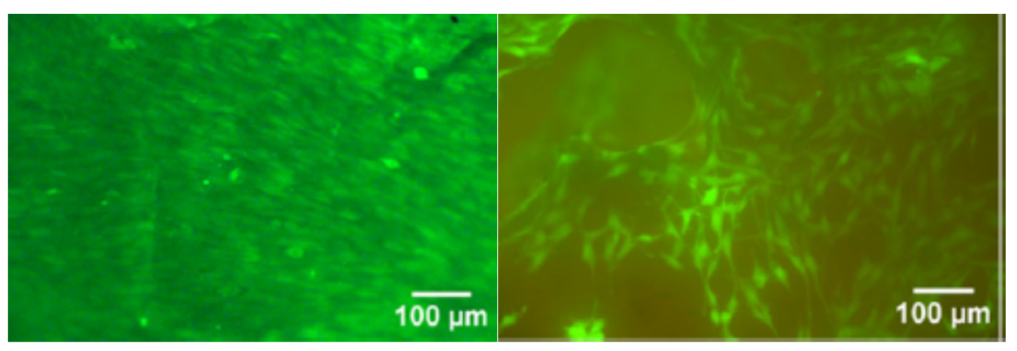

Figure 6. Live fluorescence cell staining in the glaze group (right) and the intact group (left), which indicates the reduction in the number of live cells in the intact group

Also, when using these materials in the mouth and in the vicinity of periodontium tissues deposition of salts and proteins on them, the cellular response can be different. On the one hand, during the care and brushing of this layer, the removal or change of this layer, on the other hand, is abrasion produced by toothbrush bristles can also alter the cellular response (Sjögren et al., 2000).

Based on the findings of this study, all samples except the unprepared group had a low cellular response or the response was moderate. This limit of the cellular response was considered to be clinically acceptable.

By reviewing articles that have been studying the acceptable level of cellular response, the response rate to unchanged samples was not acceptable and was interpreted as cytotoxicity (Milleding et al., 2002).

Regarding the potential for different molecules release in the samples, it seems that a better evaluation of the cellular response is needed in evaluating the amount of released molecules more accurately. However, measurement of the amount of released molecules in ceramics with many problems is due to the difficulty of isolating and precisely determining the type of molecules, and usually the tests haven't enough sensitivity to distinguish them from the variety (Tardif et al., 2004).

One of the recommended methods for performing this test is the use of radio-tops that have cytotoxic effects and are not appropriate for assessing cell activity.

Studies done to evaluate the type and amount of molecules released from modified zirconia types indicate that most of the released molecules are potassium and sodium. These molecules are less associated with inappropriate cellular response (Tardif et al., 2004).

On the other hand, the polished sample with the disks also provide some cellular response that can be associated to the preservation of the particles in porosity of the sample, although this cytotoxic activity is less than unpolished types and its biocompatibility is acceptable.

Laser glazed samples have the least inhibitory response to the cell, which seems to be due to the laser surface changes of glazed zirconia by laser and the small cellular response can be related to it. Similar studies on zirconium oxide prepared by lasers indicate that the growth of osteoblasts is better. On the one hand, studying the effect of 
glaze by the $\mathrm{CO} 2$ laser, based on the hardness tests shows a significant increase in the hardness and surface properties. Compared with the routine glaze methods, of course, the cellular response should be evaluated in the long term and after the aging process to examine the stability of the changed layer and the rate of abrasion and stability after a health habit such as tooth brushing (Kokoti et al., 2001).

The glazed samples by the standard method had the least inhibitory response, result from the change in surface produced due to fill the pores by the porcelain with lower melting temperatures and the depth of this layer was deeper than that of laser-glazing or polishing. The layer, based on studies done on its stability during the aging process and the toothbrush, seems to have long-term stability (Milleding et al., 2002).

It is recommended that a study similar to the aging process and the rational cycle of maintaining the health of the toothbrush be performed. This helps to evaluate the shelf-life of surface preparation methods and evaluate the cellular response.

\section{Conclusion}

Delivering one-stage, non-glazed-polished zirconium restorations can result in incompatible cellular response and is detrimental to the health of the periodontal tissue surrounding the restoration. It is also recommended that if the restoration due to the adjusting of clinician lose the glazed layer should not be delivered intact, at least prepare by polishing method, also if the laser is available in the clinic, then the surface restoration will be prepare using it, although it has not been routinely used due to lesser access to lasers in clinics.

Also, it doesn't seem that the rationale process for keeping hygiene with a toothbrush be effective in terms of the inhibition of this long-term restoration.

\section{References}

Amaya-Pajares, S. P., Ritter, A. V., Vera Resendiz, C., Henson, B. R., Culp, L., \& Donovan, T. E. (2016). Effect of finishing and polishing on the surface roughness of four ceramic materials after occlusal adjustment. Journal of Esthetic and Restorative Dentistry, 28(6), 382-396.

Anusavice, K. J. (1993). Recent developments in restorative dental ceramics. The Journal of the American Dental Association, 124(2), 84.

Bartolo, D., Cassar, G., Husain, N. A. H., Özcan, M., \& Camilleri, J. (2017). Effect of polishing procedures and hydrothermal aging on wear characteristics and phase transformation of zirconium dioxide. Journal of Prosthetic Dentistry, 117(4), 545-551.

Brackett, M. G., Lockwood, P. E., Messer, R. L., Lewis, J. B., Bouillaguet, S., \& Wataha, J. C. (2008). In vitro cytotoxic response to lithium disilicate dental ceramics. dental materials, 24(4), 450-456

Denry, I. L. (1996). Recent advances in ceramics for dentistry. Critical Reviews in Oral Biology \& Medicine, 7(2), 134-143.

Etman, M. K., \& Woolford, M. J. (2010). Three-year clinical evaluation of two ceramic crown systems: a preliminary study. Journal of Prosthetic Dentistry, 103(2), 80-90.

Giordano, R. A. (1996). Dental ceramic restorative systems. Compendium of continuing education in dentistry (Jamesburg, NJ: 1995), 17(8), 779-82.

Giordano, R. A., Campbell, S., \& Pober, R. (1994). Flexural strength of feldspathic porcelain treated with ion exchange, overglaze, and polishing. Journal of Prosthetic Dentistry, 71(5), 468-472.

Hammouda, I. M., Abdallah, R. M., Mohammed, M. K., Abouelatta, O. B., \& El Fallal, A. A. (2014). Laser Glazing Interaction with Dental Ceramics. British Journal of Research, 1(3).

Kilic, K., Kesim, B., Sumer, Z., Polat, Z., \& Kesim, S. (2013). In vitro cytotoxicity of all-ceramic substructural materials after aging. Journal of Dental Sciences, 8(3), 231-238.

Kohal, R. J., Weng, D., Bächle, M., \& Strub, J. R. (2004). Loaded custom-made zirconia and titanium implants show similar osseointegration: an animal experiment. Journal of Periodontology, 75(9), 1262-1268.

Kokoti, M., Sivropoulou, A., Koidis, P., \& Garefis, P. (2001). Comparison of cell proliferation on modified dental ceramics. Journal of oral rehabilitation, 28(9), 880-887.7

Martínez-Rus, F., Suárez, M. J., Rivera, B., \& Pradíes, G. (2011). Evaluation of the absolute marginal discrepancy of zirconia-based ceramic copings. Journal of Prosthetic Dentistry, 105(2), 108-114. 
Messer, R. L., Lockwood, P. E., Wataha, J. C., Lewis, J. B., Norris, S., \& Bouillaguet, S. (2003). In vitro cytotoxicity of traditional versus contemporary dental ceramics. Journal of Prosthetic Dentistry, 90(5), 452458.

Milleding, P., Haraldsson, C., \& Karlsson, S. (2002). Ion leaching from dental ceramics during static in vitro corrosion testing. Journal of Biomedical Materials Research Part A, 61(4), 541-550.

Nelson, S. K., Wataha, J. C., \& Lockwoodc, P. E. (1999). Accelerated toxicity testing of casting alloys and reduction of intraoral release of elements. Journal of Prosthetic Dentistry, 81(6), 715-720.

Oliva, J., Oliva, X., \& Oliva, J. D. (2010). Five-year success rate of 831 consecutively placed Zirconia dental implants in humans: a comparison of three different rough surfaces. International Journal of Oral \& Maxillofacial Implants, 25(2).

Rashid, H. (2012). Comparing glazed and polished ceramic surfaces using confocal laser scanning microscopy. Journal of Advanced Microscopy Research, 7(3), 208-213.

Rashid, H. (2014). The effect of surface roughness on ceramics used in dentistry: A review of literature. European journal of dentistry, 8(4), 571.

Sabaliauskas, V., Juciute, R., Bukelskiene, V., Rutkunas, V., Trumpaite-Vanagiene, R., \& Puriene, A. (2011). In vitro evaluation of cytotoxicity of permanent prosthetic materials. Stomatologija, 13(3), 75-80.

Sasaki, K., Hayashi, T., Asakura, M., Ando, M., Kawai, T., \& Ban, S. (2015). Improving biocompatibility of zirconia surface by incorporating Ca ions. Dental materials journal, 34(3), 336-344.

Sjögren, G., Sletten, G., \& Dahl, J. E. (2000). Cytotoxicity of dental alloys, metals, and ceramics assessed by millipore filter, agar overlay, and MTT tests. Journal of Prosthetic Dentistry, 84(2), 229-236.

Tardif, F., Ross, G., \& Rouabhia, M. (2004). Gingival and dermal fibroblasts produce interleukin-1 $\beta$ converting enzyme and interleukin-1 $\beta$ but not interleukin-18 even after stimulation with lipopolysaccharide. Journal of cellular physiology, 198(1), 125-132.22.

Wang, X., Xia, Y., Liu, L., Liu, M., Gu, N., Guang, H., \& Zhang, F. (2010). Comparison of MTT assay, flow cytometry, and RT-PCR in the evaluation of cytotoxicity of five prosthodontic materials. Journal of Biomedical Materials Research Part B: Applied Biomaterials, 95(2), 357-364.

\section{Copyrights}

Copyright for this article is retained by the author(s), with first publication rights granted to the journal.

This is an open-access article distributed under the terms and conditions of the Creative Commons Attribution license (http://creativecommons.org/licenses/by/4.0/). 